ORIGINAL ARTICLE

\title{
Effective emotion regulation strategies improve fMRI and ECG markers of psychopathology in panic disorder: implications for psychological treatment action
}

\author{
A Reinecke ${ }^{1}$, N Filippini ${ }^{1,2}$, C Berna ${ }^{1,2,3}$, DG Western ${ }^{4,5}$, B Hanson ${ }^{4}$, MJ Cooper ${ }^{6}$, P Taggart ${ }^{7}$ and CJ Harmer $^{1}$
}

Impairments in emotion regulation are thought to have a key role in the pathogenesis of anxiety disorders, but the neurobiological underpinnings contributing to vulnerability remain poorly understood. It has been a long-held view that exaggerated fear is linked to hyperresponsivity of limbic brain areas and impaired recruitment of prefrontal control. However, increasing evidence suggests that prefrontal-cortical networks are hyperactive during threat processing in anxiety disorders. This study directly explored limbicprefrontal neural response, connectivity and heart-rate variability (HRV) in patients with a severe anxiety disorder during incidental versus intentional emotion regulation. During 3 Tesla functional magnetic resonance imaging, 18 participants with panic disorder and 18 healthy controls performed an emotion regulation task. They either viewed negative images naturally (Maintain), or they were instructed to intentionally downregulate negative affect using previously taught strategies of cognitive reappraisal (Reappraisal). Electrocardiograms were recorded throughout to provide a functional measure of regulation and emotional processing. Compared with controls, patients showed increased neural activation in limbic-prefrontal areas and reduced HRV during incidental emotion regulation (Maintain). During intentional regulation (Reappraisal), group differences were significantly attenuated. These findings emphasize patients' ability to regulate negative affect if provided with adaptive strategies. They also bring prefrontal hyperactivation forward as a potential mechanism of psychopathology in anxiety disorders. Although these results challenge models proposing impaired allocation of prefrontal resources as a key characteristic of anxiety disorders, they are in line with more recent neurobiological frameworks suggesting that prefrontal hyperactivation might reflect increased utilisation of maladaptive regulation strategies quintessential for anxiety disorders.

Translational Psychiatry (2015) 5, e673; doi:10.1038/tp.2015.160; published online 3 November 2015

\section{INTRODUCTION}

Anxiety disorders are very common and disabling conditions that cause a particularly high economic burden, ${ }^{1-4}$ and the problem remains that not all patients show stable benefits in response to first-line intervention approaches. ${ }^{5,6}$ To improve treatments and their application, it is essential to define key mechanisms underlying anxiety disorders, as these are likely to represent important targets for treatment. Clinical models of anxiety propose that impairments in the regulation of negative affect have an important role in the pathogenesis of a disorder, as they contribute to exaggerated fear responses. ${ }^{7,8}$ Following neurobiological accounts of emotion regulation, the processing of threat involves signalling in limbic brain regions such as the amygdala, a key area implicated in the fast automatic registration of threat, whereas successful downregulation of this response is thought to be associated with increased recruitment of prefrontal areas of cognitive control. ${ }^{9,10}$ This is well supported by studies showing that in healthy volunteers, deliberate downregulation of negative affect is correlated with increased activation in medial and lateral areas of the prefrontal cortex (PFC), and that such activation dampens limbic signalling. ${ }^{11,12}$ In contrast, anxiety disorders are proposed to be associated with hyperresponsivity of limbic brain areas and impaired recruitment of prefrontal control. ${ }^{13,14}$

However, a number of novel findings suggest that while decreased allocation of lateral and ventral prefrontal resources seems to be an important characteristic of participants with nonclinical high trait anxiety or worry, ${ }^{15,16}$ activation in these areas is more likely to be increased in clinical anxiety disorders during threat processing. In particular, studies have reported increased activation in the dorsal anterior cingulate cortex (ACC) and dorsomedial PFC (dmPFC) in specific phobia, ${ }^{17}$ social anxiety disorder, ${ }^{18,19}$ panic disorder ${ }^{20,21}$ and generalised anxiety disorder. ${ }^{22}$ Similarly, anxiety-specific threat processing has increasingly been associated with heightened activation in dorsolateral (dIPFC), ${ }^{23,24}$ ventrolateral (vIPFC) $20,21,25$ and ventromedial PFC (vmPFC). ${ }^{23,26,27}$

Recent neurobiological accounts of anxiety disorders argue that, different from a view assuming reduced prefrontal cognitive control, prefrontal hyperactivation might reflect increased utilisation of dysfunctional regulation attempts in anxiety disorders. ${ }^{28,29}$ This is in line with anxiety disorders being associated with the development of avoidance and safety strategies, such as escaping the anxiety-provoking situation, or mental distraction from the threat stimulus. These avoidance-based strategies are believed to

\footnotetext{
${ }^{1}$ Department of Psychiatry, University of Oxford, Warneford Hospital, Oxford, UK; ${ }^{2}$ Centre for Functional Magnetic Resonance Imaging of the Brain, University of Oxford, Oxford, UK; ${ }^{3}$ Service d'anesthésiologie Centre Hospitalier, Universitaire Vaudois, Lausanne, Switzerland; ${ }^{4}$ Department of Mechanical Engineering, University College London, London, UK; ${ }^{5}$ Department of Mechanical Engineering, University of Bristol, Bristol, UK; ${ }^{6}$ Isis Education Centre, University of Oxford, Oxford, UK and ${ }^{7}$ Institute of Cardiovascular Sciences, University College London, London, UK. Correspondence: Dr A Reinecke, Department of Psychiatry, University of Oxford, Warneford Hospital, Oxford OX37JX, UK. E-mail: andrea.reinecke@psych.ox.ac.uk
}

Received 13 April 2015; revised 26 August 2015; accepted 6 September 2015 
Table 1. Socioeconomic, mood and anxiety self-report, negative affect ratings and heart-rate variability scores in the two groups ( $m e a n \pm$ s.d., independent-samples $t$-test $/ X^{2}$-test $P$-scores)

\begin{tabular}{|c|c|c|c|}
\hline & Panic patients & Healthy controls & P-score \\
\hline \multicolumn{4}{|l|}{ Sociodemographic data } \\
\hline Age (years) & $36.5 \pm 13.8$ & $32.3 \pm 12.1$ & 0.341 \\
\hline Gender & $\begin{array}{l}14 \text { female/ } \\
4 \text { male }\end{array}$ & $\begin{array}{l}14 \text { female/ } \\
4 \text { male }\end{array}$ & 0.655 \\
\hline Years of education & $16.6 \pm 2.7$ & $17.5 \pm 4.2$ & 0.473 \\
\hline Verbal IQ $\left(\mathrm{NART}^{45}\right)$ & $117.8 \pm 5.1$ & $118.8 \pm 3.9$ & 0.526 \\
\hline \multicolumn{4}{|c|}{ Depression and trait anxiety } \\
\hline HADS-anxiety & $14.6 \pm 4.1$ & $2.0 \pm 1.6$ & $<0.001$ \\
\hline HADS-depression & $8.1 \pm 3.4$ & $0.7 \pm 1.0$ & $<0.001$ \\
\hline \multicolumn{4}{|l|}{ Panic symptoms } \\
\hline BSQ & $3.4 \pm 0.7$ & $1.4 \pm 0.4$ & $<0.001$ \\
\hline ACQ & $2.4 \pm 0.6$ & $1.1 \pm 0.4$ & $<0.001$ \\
\hline Heart rate variability & $N=15$ & $N=13$ & \\
\hline LF/HF Maintain & $2.8 \pm 2.2$ & $1.4 \pm 1.0$ & $<0.047$ \\
\hline LF/HF Reappraisal & $2.0 \pm 1.6$ & $1.7 \pm 1.1$ & NS \\
\hline \multicolumn{4}{|l|}{ Negative affect ratings } \\
\hline Maintain & $2.8 \pm 0.6$ & $2.9 \pm 0.6$ & NS \\
\hline Reappraisal & $1.9 \pm 0.6$ & $1.9 \pm 0.7$ & NS \\
\hline \multicolumn{4}{|l|}{ State mood pre MRI scan } \\
\hline Anxious & $67.7 \pm 23.5$ & $4.3 \pm 6.1$ & $<0.001$ \\
\hline Sad & $36.6 \pm 28.9$ & $7.7 \pm 15.2$ & 0.001 \\
\hline Calm & $34.7 \pm 23.5$ & $85.0 \pm 11.2$ & $<0.001$ \\
\hline Happy & $49.3 \pm 24.4$ & $75.3 \pm 12.8$ & $<0.001$ \\
\hline \multicolumn{4}{|c|}{ State mood post MRI scan } \\
\hline Anxious & $29.9 \pm 28.1$ & $9.0 \pm 21.6$ & 0.017 \\
\hline Sad & $31.2 \pm 22.7$ & $6.1 \pm 10.9$ & $<0.001$ \\
\hline Calm & $54.3 \pm 27.4$ & $79.7 \pm 18.7$ & 0.003 \\
\hline Happy & $53.1 \pm 20.3$ & $70.8 \pm 17.3$ & 0.008 \\
\hline
\end{tabular}

Abbreviations: ACQ, Agoraphobic Cognitions Questionnaire; BSQ, Body Sensations Questionnaire; HADS, Hospital Anxiety and Depression Scale; $\mathrm{IQ}$, intelligence quotient; $\mathrm{LF} / \mathrm{HF}$, low-frequency/high-frequency heart-rate variability ratio; MRI, magnetic resonance imaging; NART, National Adult Reading Test.

have a key role in maintaining the disorder and are targeted during exposure-based cognitive-behaviour therapy (CBT). ${ }^{30,31}$ Experimental research has confirmed that during the presentation of threatening images, anxious participants are more likely to use dysfunctional regulation strategies such as suppression or cognitive avoidance. In contrast, they are less likely to use adaptive, successful techniques such as positive reappraisal. ${ }^{32,33}$ In further support of the idea of anxiety disorders being associated with an increase rather than a decrease in neural responses associated with affect regulation, CBT has been shown to lead to a decrease in responsivity in prefrontal brain areas usually implicated in cognitive control, such as the dIPFC and vmPFC. ${ }^{24,34,35}$

These results question whether anxiety involves increased or decreased engagement of prefrontal areas involved in cognitive control, and how such activation patterns are functionally connected with activation in limbic areas of the fear circuit. This study therefore aimed to assess regional neural correlates of emotion regulation in unmedicated patients with panic disorder compared with healthy volunteers, and functional connectivity between amygdala and prefrontal areas thought to be implicated in cognitive control. We therefore used a well-established emotion regulation paradigm ${ }^{12,36}$ that allows assessment of neural responses to threat images during incidental emotion regulation where pictures are viewed naturally, and intentional emotion regulation where patients use previously learned strategies of cognitive reappraisal similar to those typically taught in CBT. Furthermore, we measured beat-to-beat heart-rate variability (HRV), a measure of autonomic innervation of the brain to the heart, as an additional indicator of emotion control. ${ }^{37,38}$ Increased HRV in response to stressful stimuli reflects a dominance of the parasympathetic over the sympathetic influence and therefore successful emotion regulation. ${ }^{39}$ In line with this, reduced HRV has been reported in patients with anxiety disorders. ${ }^{40,41}$ We hypothesised that during incidental emotion regulation, patients would draw on their maladaptive regulation strategies, reflected in increased PFC activation, ineffective downregulation of limbic activation and reduced HRV. In contrast, we expected these limbic-prefrontal activation patterns and HRV reductions to be dampened during intentional regulation, where alternative, adaptive control strategies would be used.

\section{MATERIALS AND METHODS}

Participants

Following a priori power calculations, 18 unmedicated patients with panic disorder (10 with/8 without agoraphobia) naive to psychological treatment and 18 healthy controls without Diagnostic and Statistical Manual of Mental Disorders (DSM-IV) ${ }^{42}$ axis-I history were recruited from the public (Table 1). Statistical power information was derived from behavioural data gained in a previous study using a faces dot-probe task in patients versus healthy controls. ${ }^{43}$ These calculations suggested that with an alpha level of $5 \%$, sample sizes of 18 per group would be sufficient to gain statistical power of $80 \%$ (condition masked fearful faces: patients $M=31$, s.d. $=54$, controls $M=-7$, s.d. $=35$ ). Diagnoses were assessed using the Structured Clinical Interview for DSM-IV Axis I Disorders. ${ }^{44}$ Three patients fulfilled criteria for comorbid-specific phobia, with panic disorder being the primary diagnosis. General exclusion criteria were left-handedness, magnetic resonance imaging (MRI) contraindications, epilepsy, history of psychotic, bipolar or substance abuse disorder, and antidepressant treatment during the last 6 months. Three patients having reported occasional (but not regular) on-demand benzodiazepine or propranolo intake were medication-free $48 \mathrm{~h}$ before scanning. Ethical approval was obtained from the local research ethics committee.

\section{Mood and subjective state}

Participants completed the Hospital Anxiety and Depression Scale, ${ }^{46}$ Body Sensations Questionnaire and Agoraphobic Cognitions Questionnaire. ${ }^{47}$ Before and after the scan, they completed Visual Analogue Scales for the dimensions anxious, sad, calm and happy $(0-100 \mathrm{~mm}$, not at all-extremely) to assess state mood.

\section{fMRI task design}

Stimuli were 40 negatively valenced coloured IAPS images ${ }^{48}$ picturing characteristic panic-related catastrophic expectations, such as accidents or funerals (mean valence ratings $2.8 \pm 1.7$, mean arousal ratings $6.0 \pm 2.2$ on 9-point Likert scales ranging from $1=$ unpleasant/low arousal to $9=$ pleasant/high arousal). Valence and arousal ratings as well as scene content were matched between the two experimental conditions Maintain and Reappraisal. The order of picture blocks remained constant across all participants, with half of the subjects per group starting with a Maintain and half starting with a Reappraisal block.

Pictures were presented in eight blocks of five images, one after another for $5 \mathrm{~s}$ each, separated by $1-\mathrm{s}$ blank screen interstimulus intervals. Picture blocks alternated with grey fixation baseline blocks of $30 \mathrm{~s}$, and experiments started with a baseline block. For half of the blocks, participants were instructed to passively view the images and naturally experience the emotional state evoked, without attempting to regulate or alter it (Maintain blocks). For Reappraisal blocks, they were instructed to downregulate the provoked negative affect by using strategies of cognitive reappraisal (for example, reframing, rationalising). These strategies were trained before the scan using different images. Instructions were given by presenting the word Maintain or Reappraise on screen for $4 \mathrm{~s}$ before a block. At the end of each picture block, a 4-point rating scale 
( 1 = neutral, 4 =negative) was presented for $4 s$, and participants indicated the intensity of negative affect experienced throughout the block using a keypad. The total task duration was $\sim 10 \mathrm{~min}$.

\section{ECG recording}

Throughout functional scanning, three-electrode electrocardiogram (ECG) was recorded to calculate HRV, separately for Maintain and Reappraisal blocks, using Siemen's PERU system (Erlangen, Germany). Signals were processed using custom algorithms. ${ }^{49}$ In brief, heart beats were timed at the instants of R-wave peaks in the ECG signal, and heart rate was measured as the inverse of consecutive R-wave to R-wave interval period. The timing of individual heart beats was automatically identified and manually corrected. The intervals between beats were calculated to construct a time series over the course of the experiment representing variations in the subject's heart rate. This series was then used to calculate low-frequency (LF; 0.04-0.15 Hz) and high-frequency (HF; 0.15-0.4 Hz) HRV parameters, using the spectral averaging technique. ${ }^{50}$ These parameters were calculated separately for Maintain versus Reappraisal blocks.

\section{Image acquisition}

Images were obtained using a 3-T Siemens Sonata scanner. Functional imaging data were analysed using FEAT 6.0, part of FSL (FMRIB Software Library; fmrib.ox.ac.ul/fsl) with $Z>2.3$ and $P<0.05$, including multiplecomparison corrections. $T_{2}{ }^{*}$-weighted functional data were acquired for a whole-brain field of view $(64 \times 64 \times 40$ matrix, 45 slices, voxel resolution $3 \mathrm{~mm}^{3}$, gap $1.5 \mathrm{~mm}$, repetition time $=3000 \mathrm{~ms}$, echo time $=30 \mathrm{~ms}$, flip angle $=90^{\circ}$ ). Field maps were acquired using a dual-echo two-dimensional gradient echo sequence with echos at 5.19 and $7.65 \mathrm{~ms}$, and a repetition time of $500 \mathrm{~ms}$. High-resolution $\mathrm{T}_{1}$-weighted images were acquired for subject alignment, using an MPRAGE sequence $(174 \times 192 \times 192$ matrix, voxel resolution $1 \mathrm{~mm}^{3}$, repetition time $=2040 \mathrm{~ms}$, echo time $=4.7 \mathrm{~ms}$, inversion time $=900 \mathrm{~ms}$ ).

\section{Image analysis}

Event-related analysis. $\mathrm{T}_{2}$ pre-processing included motion correction, ${ }^{51}$ non-brain removal, ${ }^{52}$ spatial smoothing (Gaussian kernel full width at half maximum $=5.0 \mathrm{~mm}$ ), grand-mean intensity normalisation of the entire four-dimensional data set by a single multiplicative factor, registration of the functional space template to the anatomical space and the Montreal Neurological Institute (MNI) 152 space, highpass temporal filtering (Gaussian-weighted least-squares straight line fitting, with sigma $=50.0 \mathrm{~s}$ ), fieldmap correction. At the first-level, data were analysed using a general linear model approach with local autocorrelation correction. ${ }^{53}$ Two regressors of interest (Maintain, Reappraise) and two regressors of no interest (instruction/rating periods) were included. Fixation blocks were the implicit baseline reference. Contrast images were calculated for picture blocks in general, Maintain blocks, Reappraisal blocks, Maintain versus Reappraisal and Reappraisal versus Maintain. These individual activation maps were then entered into the group level (patients and controls), using a mixed-effects analysis across the whole brain. ${ }^{54}$ Due to strong evidence implicating the periamygdala region in threat processing using an almost identical task, ${ }^{55}$ region-of-interest (ROI) analyses were carried out for a 10$\mathrm{mm}$ radius spherical mask around a previously published peak voxel (-14/ $-6 /-8$; and right-hemisphere counterpart). ${ }^{12}$ Significant whole-brain or $\mathrm{ROI}$ interactions were explored by (i) extracting BOLD signal changes within these areas and entering these into group $\times$ task mixed-design analyses of variance (ANOVAs) and appropriate follow-up $t$-tests, and (ii) running Pearson's correlation analyses for the percent signal change and panic symptom severity (calculated as the mean of the scores achieved on the Agoraphobic Cognitions Questionnaire and Body Sensations Questionnaire)

Connectivity analyses. We closely based this analysis on previous work showing that the onset of threat stimuli alters functional connectivity with an anatomy-based amygdala functional cluster. ${ }^{56}$ For each participant, we extracted a deconvolved time series for the functional cluster identified in the anatomical (i) right amygdala mask (peak: $26,0,-14 ; Z=6.3$ ) and (ii) left amygdala (peak: $-22,-4,-12 ; Z=6.7$ ), in the pictures versus baseline contrast across groups, using small volume correction. These time courses were entered in two FSL psychophysical interaction analyses, separated for the functional right amygdala versus left amygdala cluster as seed region, along with the two psychological regressors (Maintain and Reappraisal), the two psychophysical interaction regressors (Maintain $\times$ time series and
Reappraisal $\times$ time series) and the regressors of no interest (instructions and ratings). These individual contrast images were then entered into the group level, using a mixed-effects analysis across the whole brain, in order to identify brain areas that showed activity that covaried stronger with that of the left and right amygdala in one of the two groups during Maintain blocks, Reappraisal blocks or picture blocks in general. Pearson's correlations were computed for standardised betas (extracted from significant clusters) and panic symptom severity (calculated as the mean of the scores achieved on the Agoraphobic Cognitions Questionnaire and Body Sensations Questionnaire).

Given previous research indicating increased amygdala-dmPFC connectivity during the anticipation of threat ${ }^{56,57}$ and in anxiety disorders, ${ }^{58}$ strength of coupling between the amygdala seed regions and the dmPFC was identified using a ROI approach. We extracted regression standardised beta values reflecting coactivation between the amygdala seeds and a 10$\mathrm{mm}$ radius drawn around 12/42/54, a previously published peak voxel of a dmPFC cluster relevant in emotion regulation using an identical task and instructions, ${ }^{12}$ and entered these into group $\times$ task ANOVAs and Pearson's correlation analyses (panic severity).

Voxel-based morphometry. Voxel-based morphometry was carried out to be able to add grey matter maps as covariates to the functional MRI (fMRI) analysis model, to only identify group differences in functional activation that reflect cognitive-emotional rather than grey matter differences. Brain extraction and tissue-type segmentation were performed and resulting grey matter partial volume images were aligned to standard space using first linear (FLIRT) and then non-linear (FNIRT) registration tools. The resulting images were averaged, modulated and smoothed with an isotropic Gaussian kernel of $7 \mathrm{~mm}$ full width at half maximum to create a study-specific template, and the grey matter images were re-registered to this, including modulation by the warp field Jacobian. Threshold-freecluster-enhancing correction was applied. Finally, voxel-wise general linear modelling was applied using permutation nonparametric testing (5000 permutations), correcting for multiple comparisons across space.

\section{RESULTS}

\section{Affect ratings and behavioural data}

Mood and anxiety measures. Patients reported significantly higher trait anxiety and depression (Hospital Anxiety and Depression Scale) levels than controls, and they showed more fear of physical sensations (Body Sensations Questionnaire) (Table 1). With respect to state mood, there were significant group differences on all Visual Analogue Scales taken before and after the scan (Table 1). Patients showed lower anxiety scores and higher calm scores after the scan compared with baseline (both $t>3.20$, both $P<0.005$ ).

HRV and negative affect ratings during scan. Differences were analysed performing group $\times$ task mixed-model ANOVAs. In patients but not controls, LF/HF ratio was higher in Maintain compared with Reappraisal blocks (Table 1; group $\times$ task $F=5.89$, $\mathrm{df}=1 / 26, P=0.023, d=0.83$; paired-samples $t$-test $t=2.14, \mathrm{df}=14$, $P=0.049$ ). During Maintain blocks, patients showed higher LF/HF ratios than controls (independent samples $t=2.09, \mathrm{df}=26$, $P=0.047, d=0.82$ ), suggesting reduced HRV and more sympathetic compared with parasympathetic activation. Groups were not significantly different in LF/HF ratio during Reappraisal $(t=0.52, \mathrm{df}=26, P=0.606)$.

Negative affect ratings were lower in Reappraisal versus Maintain blocks in both groups, without between-group differences (Table 1; Task $F=45.26$, $\mathrm{df}=1 / 34, P<0.001$; group/group $\times$ task both $F<0.04$, both $P>0.855$ ).

\section{BOLD fMRI}

\section{Whole-brain analysis}

Main effect of task (Reappraise versus Maintain, across groups): Reappraisal was associated with increased activation in bilateral dorsal ACC, dmPFC, dIPFC, vIPFC, angular gyri, superior lateral occipital cortices, orbitofrontal cortices/subcollosal 
a

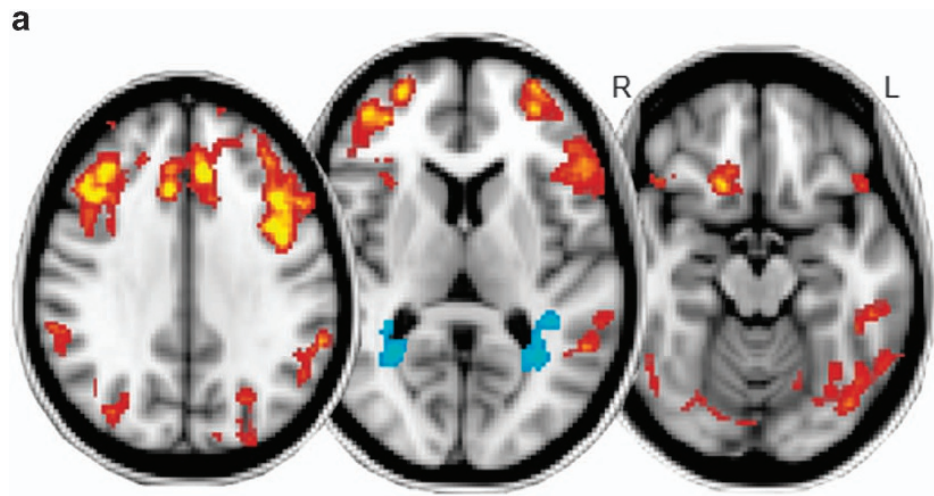

b

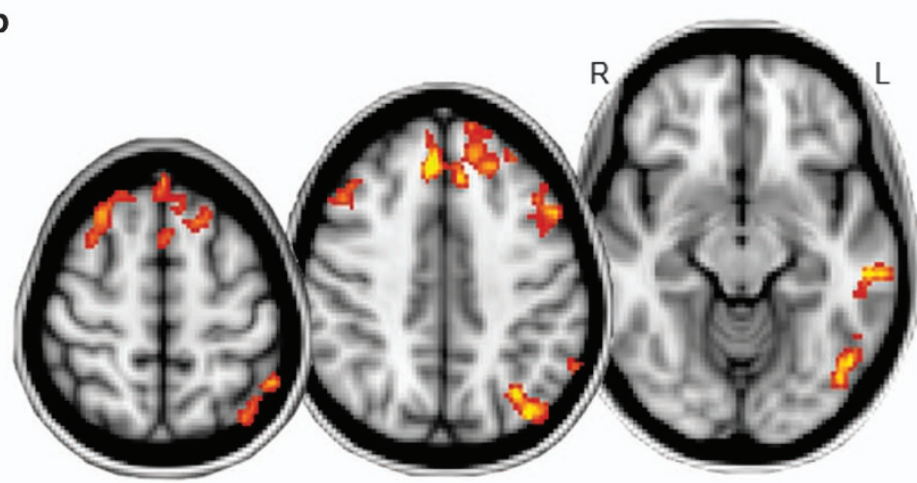

C
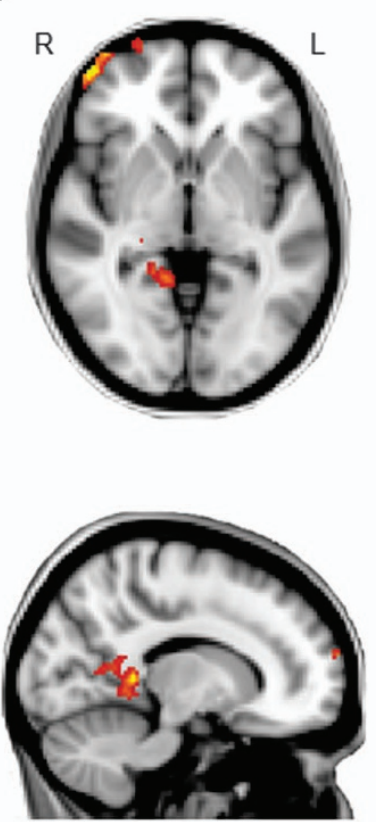

$0 \square-4$

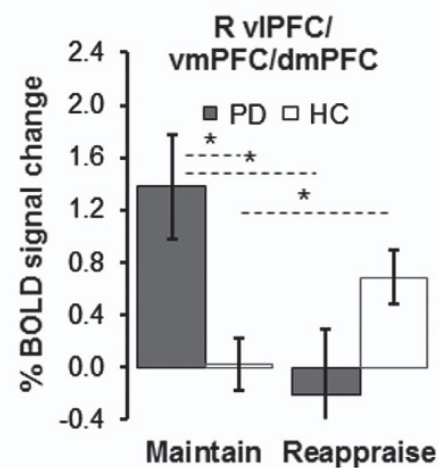

R hippocampus ext.

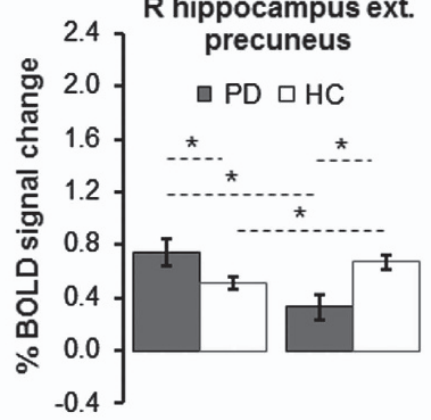

Maintain Reappraise
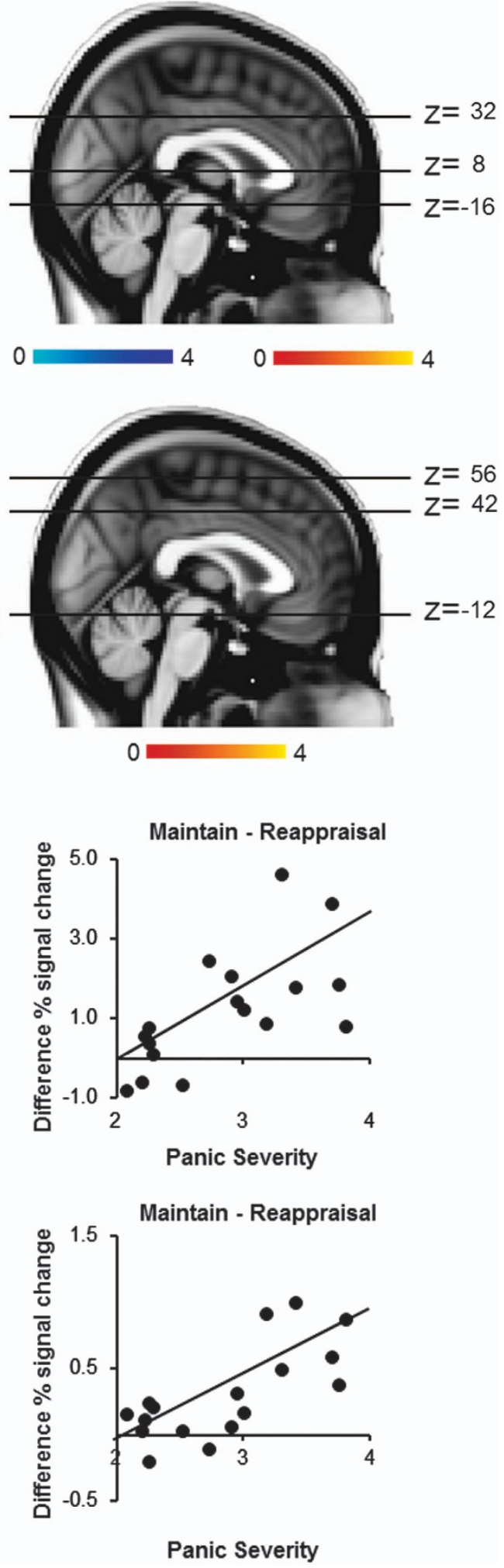

cortices/caudate, cerebellum/occipital fusiform/inferior temporal gyrus, and left middle temporal gyrus. Reappraisal also led to significant deactivation in bilateral precuneus/lingual gyrus (Figure 1a; Table 2A).

Main effect of group (picture blocks versus baseline): Compared with controls, patients showed significantly higher activation in bilateral dmPFC and dIPFC, left dorsal ACC and right supplementary motor area, as well as left inferior frontal gyrus, left middle temporal gyrus, left inferior and superior lateral occipital cortex, left occipital fusiform gyrus and left angular gyrus during the eight picture blocks versus the fixation screen baseline (Figure 1b; Table 2B; all $d>1.19$ ). Percent signal change in these clusters was 
Figure 1. Whole-brain fMRI results. All images thresholded at $Z>2.3, P<0.05$, corrected. (a) Main effect of task: across both groups, Reappraisal (versus Maintain) led to greater BOLD signal response in bilateral dorsal anterior cingulate cortex, dorsomedial, dorsolateral, and ventrolateral PFC, orbitofrontal cortex, lateral occipital cortex, angular gyrus, cerebellum and occipital fusiform and inferior temporal gyri, and left middle temporal gyrus, and to a decrease in activation in bilateral precuneus ext. lingual gyrus. (b) Main effect of group: compared with controls, patients showed increased activation in prefrontal, temporal and occipital areas, including bilateral dorsomedial and dorsolateral PFC, left dorsal anterior cingulate cortex, right supplementary motor area, left inferior frontal and middle temporal gyri, left lateral occipital cortex and occipital fusiform gyrus, and left angular gyrus during picture blocks (versus fixation baseline block). (c) Group $\times$ task interaction: maintaining negative affect (versus Reappraisal) was associated with increased signal response in patients compared with controls in a right frontal pole cluster including the vIPFC, vmPFC and dmPFC (top panel), and a limbic cluster including parts of the right hippocampus, posterior cingulate cortex, precuneus and lingual gyrus (bottom panel). In controls, Maintain (versus Reappraisal) was related to decreased activation in this limbic cluster. For both clusters, BOLD\% signal change during Maintain minus Reappraisal blocks was significantly correlated with symptom severity in patients. MNI coordinates 14,-42,-2. Error bars show s.e.m. *Significant difference between conditions or groups. dmPFC, dorsomedial PFC; ext., extending into; HC, healthy control; L, left; PD, panic disorder patient; PFC, prefrontal cortex; R, right; vIPFC, ventrolateral PFC; vmPFC, ventromedial PFC.

Table 2. (A) Areas of significant increase and decrease in BOLD response during voluntary emotion regulation (Reappraisal versus Maintain) across both groups. Areas of significant increase in BOLD response in patients versus controls during (B) picture blocks versus fixation baseline blocks, and (C) Maintain versus Reappraisal blocks. MNI coordinates refer to the peak activation voxel of the cluster and main sub-regions within the same cluster (significant group differences are in bold)

\begin{tabular}{|c|c|c|c|c|c|c|}
\hline & $B A$ & Side & Cluster size (voxels) & $M N I(x, y, z)$ & Z-score & P-score \\
\hline \multicolumn{7}{|l|}{ (A) Main effect of task across groups } \\
\hline \multicolumn{7}{|l|}{ Increased activity during reappraisal $(R>M)$} \\
\hline Dorsal ACC ext. dorsomedial PFC & 6/8/32 & $\mathbf{L}$ & 14701 & $-4,20,50$ & 5.86 & $<0.001$ \\
\hline Dorsal ACC ext. dorsomedial PFC & $6 / 8 / 32$ & $\mathrm{R}$ & & $4,28,40$ & 4.99 & \\
\hline Ventrolateral ext. dorsolateral PFC & $9 / 45 / 46$ & $\mathrm{R}$ & & $36,46,12$ & 4.9 & \\
\hline Cerebellum ext. occipital fusiform/inferior temporal gyri & $19 / 37$ & $\mathbf{L}$ & 7274 & $-36,-64,-28$ & 4.30 & $<0.001$ \\
\hline Middle temporal gyrus & $20 / 21$ & L & & $-60,-32,0$ & 4.2 & \\
\hline Angular gyrus & $39 / 40$ & $\mathrm{R}$ & & $44,-60,42$ & 4.18 & \\
\hline Superior lateral occipital cortex & $5 / 7$ & $\mathrm{R} / \mathrm{L}$ & & $0,-68,68$ & 4.06 & \\
\hline Angular gyrus & $39 / 40$ & L & & $-60,-44,34$ & 4.06 & \\
\hline Cerebellum ext. occipital fusiform/inferior temporal gyri & $19 / 37$ & $\mathbf{R}$ & 2184 & $36,-60,-52$ & 4.46 & $<0.001$ \\
\hline Frontal orbital cortex & $11 / 38$ & $\mathbf{R}$ & 544 & $16,22,-16$ & 3.92 & 0.006 \\
\hline Subcallosal cortex ext. caudate & 25 & $\mathrm{R}$ & & $6,20,-12$ & 3.89 & \\
\hline Subcallosal cortex ext. caudate & 25 & L & & $-4,8,-10$ & 3.29 & \\
\hline \multicolumn{7}{|l|}{ Decreased activity during reappraisal $(M>R)$} \\
\hline Precuneus ext. lingual gyrus & 19 & $\mathbf{R}$ & 477 & $26,-32,22$ & 3.67 & 0.014 \\
\hline Precuneus ext. lingual gyrus & 19 & $\mathbf{L}$ & 434 & $-20,-42,24$ & 3.90 & 0.024 \\
\hline \multicolumn{7}{|l|}{ (B) Pictures vs baseline/patients vs controls } \\
\hline Dorsal anterior cingulate cortex & 32 & L & 1352 & $-8,28,38$ & 3.99 & $<0.001$ \\
\hline Dorsomedial PFC & $8 / 9$ & L & & $-24,38,46$ & 3.65 & \\
\hline Dorsomedial PFC & $8 / 9$ & $\mathrm{R}$ & & 4,42,46 & 3.56 & \\
\hline Supplementary motor area & 6 & $\mathrm{R} / \mathrm{L}$ & & $4,14,72$ & 3.55 & \\
\hline Dorsolateral PFC & 45 & $\mathbf{L}$ & 799 & $-46,30,28$ & 3.90 & $<0.001$ \\
\hline Inferior frontal gyrus & $44 / 48$ & $\mathrm{~L}$ & & $-54,16,14$ & 3.88 & \\
\hline Dorsolateral PFC & 46 & L & & $-40,34,26$ & 3.65 & \\
\hline Dorsolateral PFC & 9 & $\mathrm{~L}$ & & $-42,18,44$ & 3.50 & \\
\hline Middle temporal gyrus ext. inferior lateral occipital cortex & $20 / 21$ & $\mathbf{L}$ & 535 & $-56,-28,-12$ & 3.77 & 0.003 \\
\hline Occipital fusiform gyrus & 37 & $\mathrm{~L}$ & & $-48,-66,-12$ & 3.53 & \\
\hline Inferior lateral occipital cortex & 19 & L & & $-44,-74,-14$ & 3.33 & \\
\hline Superior lateral occipital cortex & 7 & $\mathbf{L}$ & 493 & $-32,-68,40$ & 3.97 & 0.006 \\
\hline Angular gyrus & 40 & L & & $-50,-52,54$ & 3.61 & \\
\hline Dorsomedial PFC & 9 & $\mathbf{R}$ & 459 & $20,36,54$ & 3.30 & 0.009 \\
\hline Dorsolateral PFC & 44 & $\mathrm{R}$ & & $50,18,38$ & 3.28 & \\
\hline Dorsolateral PFC & $8 / 9$ & $\mathrm{R}$ & & $42,18,50$ & 3.19 & \\
\hline \multicolumn{7}{|l|}{ (C) Maintain vs reappraise/patients vs controls } \\
\hline Ventrolateral PFC & $46 / 47$ & $\mathbf{R}$ & 417 & $48,56,-2$ & 3.98 & 0.030 \\
\hline Ventromedial/dorsomedial PFC & $10 / 11$ & $\mathrm{R}$ & & $32,68,2$ & 3.15 & \\
\hline Hippocampus ext. precuneus/posterior cingulate & $27 / 29 / 30 / 37$ & $\mathbf{R}$ & 387 & $14,-42,4$ & 3.80 & 0.044 \\
\hline Hippocampus & 27 & $\mathrm{R}$ & & $24,-34,-12$ & 3.65 & \\
\hline Lingual gyrus & 37 & $\mathrm{R}$ & & $26,-42,-8$ & 3.16 & \\
\hline Precuneus & 30 & $\mathrm{R}$ & & $12,-52,10$ & 3.04 & \\
\hline
\end{tabular}

Abbreviations: ACC, anterior cingulate cortex; BA, Brodmann area; ext., extending into; L, left; $M>R$, Maintain versus Reappraisal; MNI, Montreal Neurological Institute; PFC, prefrontal cortex; $\mathrm{R}$, right; $R>M$, reappraisal versus maintain. 

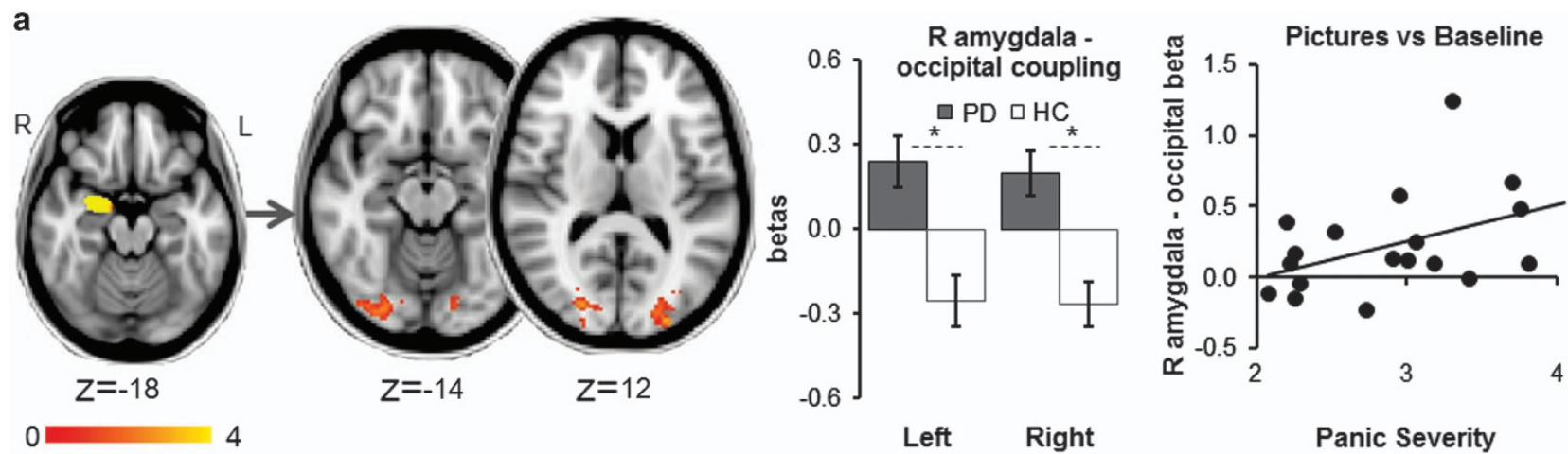

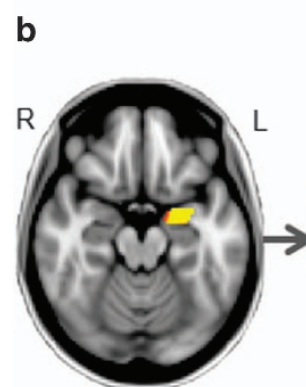

$z=-18$

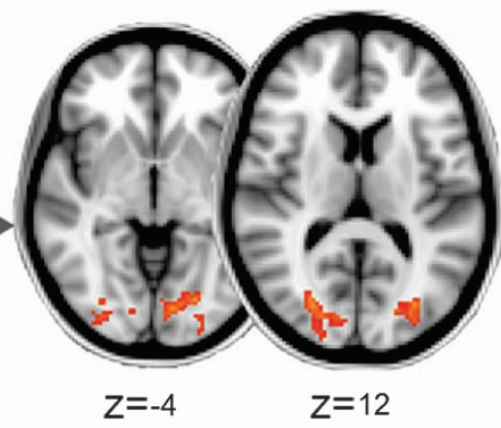

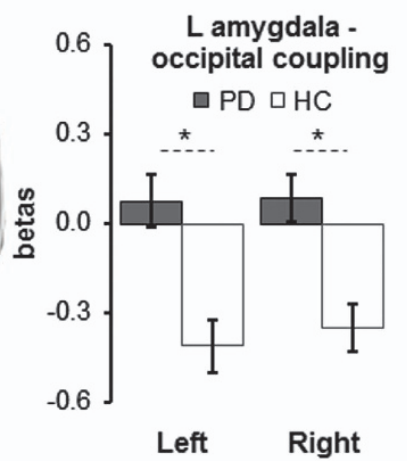

Panic Severity

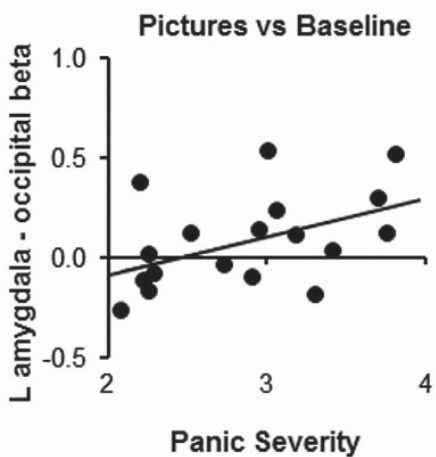

Figure 2. Whole-brain psychophysical interaction analysis with a right amygdala (a) and left amygdala (b) functional cluster (picture blocks versus baseline, across groups) as the seed region: patients showed higher connectivity of the right and left amygdala with left and right occipital pole, occipital fusiform gyrus, lateral occipital cortex and lingual gyrus. In patients, coupling between right amygdala seed and occipital cortex clusters and left amygdala seed and occipital cortex clusters was positively correlated with panic severity. Images thresholded at $Z>2.3, P<0.05$, corrected. *Significant difference between groups. Error bars show s.e.m. HC, healthy control; L, left; PD, panic disorder patient; $R$, right.

not correlated with panic symptom severity in any of the groups (all $r<0.26, P>0.293$ ).

Group $\times$ task interaction (Maintain versus Reappraise): Results showed a significant group $\times$ task interaction in a frontal pole cluster spanning the right vIPFC and the right dmPFC and vmPFC, as well as a limbic cluster including parts of the right dorsal hippocampus and posterior cingulate, precuneus and lingual gyrus (Figure 1c; Table 2C). Post hoc analyses on BOLD signal change extracted from each of the two clusters indicated that the PFC interaction was driven by a group difference in response to pictures during Maintain blocks (ANOVA task $\times$ group $F=14.79$, $\mathrm{df}=1 / 34, P=0.001, d=1.32$ ), with patients showing significantly higher activation than controls (Maintain $t=2.77, \mathrm{df}=34, P=0.009$, $d=0.80$; Reappraise $t=1.60, \mathrm{df}=34, P=0.119, d=0.55)$. The group $\times$ task interaction in the hippocampal cluster was based on patients showing an increase in activation in this area in the Maintain condition and a decrease during Reappraisal (group $x$ task interaction $F=14.83, \mathrm{df}=1 / 34, P<0.001, d=1.32$; post hoc $t$-tests Maintain $t=2.05, \mathrm{df}=34, P=0.048, d=0.63$; Reappraise $t=2.93, \mathrm{df}=34, P=0.006, d=1.14$ ). In patients but not controls, BOLD activation in both these clusters during Maintain minus Reappraisal blocks was positively correlated with panic severity (PFC: patients $r=0.49, P=0.038$, controls $r=0.36, P=0.142$; hippocampus: patients $r=0.49, P=0.038$; controls $r=-0.23$, $P=0.369$ ). However, these do not survive conservative Bonferroni correction (that is, required $P<0.025$ ).

ROI analysis: A hemisphere $\times$ group $\times$ task ANOVA for the BOLD percent signal change extracted for the left (Maintain: patients $0.40 \pm 0.44$, controls $0.15 \pm 0.17$; Reappraise: patients $0.11 \pm 0.36$, controls $0.19 \pm 0.22$ ) and right amygdala (Maintain: patients $0.37 \pm 0.55$, controls $0.13 \pm 23$; Reappraise: patients $0.10 \pm 0.37$, controls $0.17 \pm 0.24)$ spheres revealed a significant group $\times$ task interaction $\left(F=6.82, \mathrm{df}=1 / 34, P_{\text {Bonferroni }}=0.026, d=0.90\right)$, without any laterality differences (all $F<0.10$, all $P_{\text {Bonferroni }}>0.998$ ). This effect was driven by patients showing higher activation than controls in Maintain blocks $\left(t=2.43, \mathrm{df}=34, P_{\text {Bonferroni }}=0.042\right.$, $d=0.81)$. In patients $(r=0.42, P=0.043)$ but not controls $(r=-0.13$, $P=0.613)$, Maintain minus Reappraisal BOLD percent signal change in the amygdala was positively correlated with panic symptom severity.

\section{Connectivity analyses}

Whole-brain results: In patients versus controls, activity in each amygdala during picture blocks (versus baseline) was significantly more strongly correlated with activity in the left and right occipital cortices, occipital poles, occipital fusiform gyri and lingual gyri (right amygdala: right (R) cortical cluster: 591 voxels, MNI $14,-84,4, \quad Z=3.86 /$ left (L) cortical cluster: 511 voxels, MNI $-10,-84,-4, Z=3.61$; left amygdala: $R$ cortical cluster: 578 voxels, MNI $28,-80,2, Z=3.67 / \mathrm{L}$ cortical cluster: 461 voxels, MNI $-10,-84,-2, Z=3.47$; all $d>1.25$ ). In patients but not controls, the magnitudes of right amygdala-occipital clusters and left amygdala-occipital clusters coupling were positively correlated with symptom severity (patients: L/R amygdala-occipital clusters both $r>0.42$, both $P<0.042$; controls: L/R amygdala-occipital clusters both $r>0.35$, both $P>0.078$ ) (Figure 2).

Amygdala-dorsomedial PFC coupling: For the right amygdala seed, we found a significant group $\times$ task interaction driven by patients showing higher right amygdala-right dmFC connectivity than controls during Maintain blocks (ANOVA group $\times$ task $F=7.17, \mathrm{df}=1 / 34, P_{\text {Bonferroni }}=0.022, d=0.92 ; t$-test $t=2.39, \mathrm{df}=$ $34, P_{\text {Bonferroni }}=0.046, d=0.80$ ). For the left amygdala seed, the 


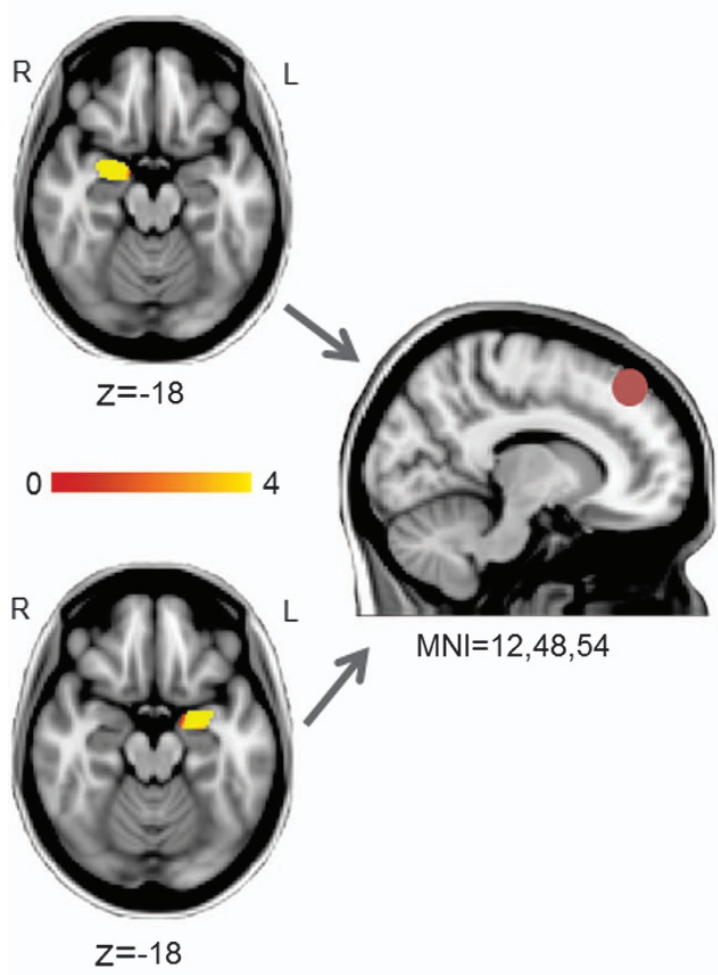

b

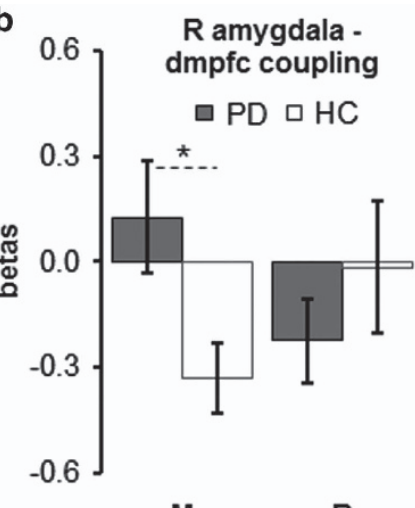

M

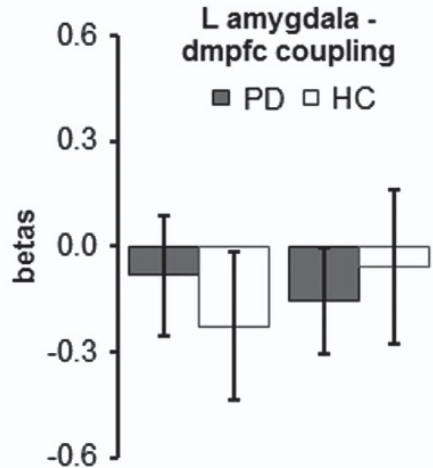

M
$\mathbf{R}$
Maintain - Reappraisal

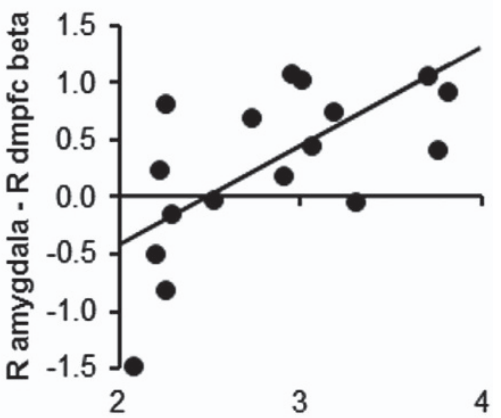

Panic Severity

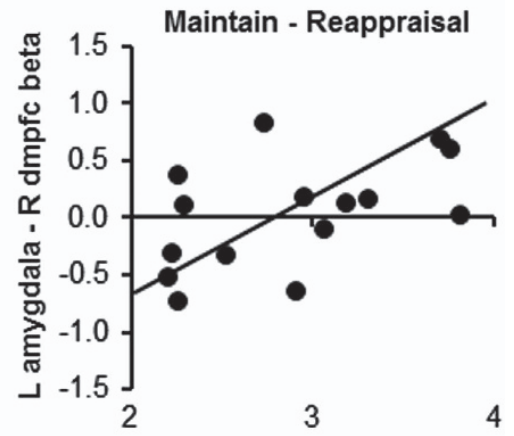

Panic Severity

Figure 3. Psychophysiological interaction analyses exploring connectivity of activity within the right amygdala (a) and left amygdala (b) as seed regions and a right dorsomedial prefrontal cortex $(\mathrm{R} \mathrm{dmpfc})$ region of interest. The right amygdala showed a task $\times$ group interaction in connectivity with the dmpfc, with amygdala-dmpfc coupling being significantly greater in patients relative to controls during Maintain blocks. No such significant interaction was found for the left amygdala seed. In patients, higher right amygdala-dmpfc coupling, as well as higher left amygdala-dmpfc coupling during Maintain minus Reappraisal blocks were associated with higher panic severity. ${ }^{*}$ Significant difference between groups. HC, healthy control; L, left; MNI, Montreal Neurological Institute; PD, panic disorder patient; R, right.

ANOVA yielded no group $\times$ task interaction $(F=0.27, \mathrm{df}=1 / 34$, $\left.P_{\text {Bonferroni }}=0.904\right)$. In patients but not controls, the magnitudes of right amygdala-dmPFC coupling and left amygdala-dmPFC coupling during Maintain minus Reappraisal blocks were positively correlated with panic symptom severity (patients: L/R amygdala-dmPFC clusters both $r>0.55$, both $P<0.010$; controls: L/R amygdala-dmPFC clusters both $r<0.20$, both $P>0.214$ ) (Figure 3).

Voxel-based morphometry: No group differences were observed in grey matter concentration. Furthermore, BOLD group contrast differences were not affected by adding individual grey matter maps as covariates to the fMRI analysis model, and they survived as clear differences between the two groups, suggesting that they reflect cognitive-emotional differences rather than being driven by sub-threshold grey matter differences between groups.

\section{DISCUSSION}

We believe this is the first study to simultaneously explore regional neurofunctional activation and limbic-prefrontal connectivity in patients with an anxiety disorder during incidental versus intentional emotion regulation. In line with our hypotheses, we found a pattern of increased brain activation in patients compared with controls in both limbic and prefrontal areas during incidental emotion regulation (Maintain) and in response to images in general. These differences were reduced, or even reversed, during intentional regulation (Reappraisal). The differences in brain activity were accompanied by significantly reduced heart rate variability in patients versus controls during incidental regulation only, highlighting patients' ability to regulate emotional response given appropriate cognitive strategies. Although these results challenge influential models of fear that propose impaired allocation of PFC resources as a neurobiological basis for the development of an anxiety disorder, ${ }^{13,14}$ they are well in line with more recent frameworks. ${ }^{28,59}$

In the neurobiological hypervigilance-avoidance model, Hoffman et al. $^{28}$ postulate that threat processing in anxiety is associated with two different sets of functional activation patterns: hypervigilance processes and maladaptive, avoidant emotion regulation processes. The hypervigilance processes are thought to include amygdala hyperactivation in response to the detection of threat, which in turn facilitates visual processing in the occipital cortex. This is thought to enhance processes of selective attention and monitoring in the dmPFC while recruiting the hippocampus to provide information about memory associations with the potential threat stimulus. ${ }^{28,59}$ The maladaptive regulation processes are thought to include hyperactivation in a range of ventral and lateral prefrontal-cortical regions known to be implicated in regulating negative emotional reactivity.

In line with the assumed hypervigilance circuit, our patients showed increased activation in occipital areas, dorsal mPFC and ACC, and increased amygdala-occipital connectivity when viewing threat images in general. They also demonstrated amygdala and hippocampus hyperactivation and increased amygdaladmPFC connectivity during Maintain (versus Reappraisal) blocks. Most of these parameters correlated positively with symptom 
severity. These results also fit in well with other recent imaging studies, suggesting that threat processing in anxiety disorders is associated with increased activity in amygdala, hippocampus $21,25,26,60,61,62$ and occipital cortex, ${ }^{27,62}$ or in dorsal ACC and mPFC, ${ }^{17-22}$ areas that have been implicated in selective attention, threat bias and monitoring. .6,63-68 $^{\text {. }}$

The results are also in line with prior studies demonstrating increased functional amygdala-dmPFC connectivity during the anticipation of threat in healthy volunteers, ${ }^{56,57}$ with additional increases in subjects with higher trait anxiety, neuroticism or anxiety disorders. ${ }^{56-58}$ Furthermore, increased attentional bias magnitude derived from behavioural tasks has been shown to be correlated with increased amygdala-dorsal ACC connectivity in healthy volunteers, ${ }^{69}$ providing further evidence that such brain activation patterns might predispose patients to selectively focus their attention to threat information in their environment. The potential role of these proposed areas of hypervigilance in the psychopathology of anxiety disorders is further supported by clinical research showing a reduction of activation in amygdala, ${ }^{17,70}$ hippocampus, ${ }^{24}$ dorsal $\mathrm{mPFC}$ and $\mathrm{ACC}^{17}$ following successful CBT.

The assumption that hyperactivation in lateral and ventral prefrontal-cortical regions might reflect anxiety-specific dysfunctional regulation strategies is supported by our findings of patients showing increased activation in dorsal and ventral lateral PFC in response to threat images in general. Furthermore, they showed increased response in VMPFC and vIPFC during incidental regulation, with activation strength correlating positively with panic severity. Lateral prefrontal activation has previously been implicated in intentional emotion regulation ${ }^{11,71,72}$ and inhibitory control, ${ }^{73,74}$ and the vmPFC has particularly been associated with automatic conflict and emotion regulation ${ }^{75-77}$ in healthy volunteers. In line with our observations, other imaging studies exploring threat processing in anxiety disorders have reported heightened activation in the dIPFC, ${ }^{23,24}$ vIPFC $^{20,21,25}$ and vmPFC, $^{23,26,27}$ and CBT has been shown to significantly reduce such hyperactivation. ${ }^{34,35}$

Taken together, our results provide evidence in favour of recent models of anxiety, which propose that psychopathology might be underpinned by hyperactivation in both limbic and prefrontalcortical brain regions in response to threat. ${ }^{28,59}$ Such findings contradict previous frameworks postulating that impaired emotion regulation in anxiety is correlated with reduced recruitment of PFC areas of top-down control. ${ }^{13,14}$ Strikingly, these early models were greatly based on research investigating neural processing in high trait anxiety or post-traumatic stress disorder (PTSD), which appear to characteristically be associated with decreased recruitment of PFC resources during threat processing. ${ }^{29}$ Neurobiological activation patterns in high trait anxiety in response to threat might still be adaptive and as such distinctive from activation patterns in anxiety disorders. Notably, PTSD is not classified as an anxiety disorder in DSM-V (APA, 2013) anymore, as the key symptom is the re-experience of a de facto trauma rather than arbitrary fear, and as fear is not the only and not necessarily the predominant emotion. $^{78,79}$ It appears plausible that these differences in aetiology and symptomatology between PTSD and anxiety disorders might be underpinned by differences in neurobiological pathophysiology, and future research will have to address these issues explicitly. It is also possible that differences in paradigms used between studies might contribute to contrary findings in prefrontal-cortical activation, with previous studies in trait anxiety often tapping into rapid resolution of emotional conflict ${ }^{13}$ rather than emotion processing and regulation per se.

It might appear puzzling why we rarely found group differences in functional activation for reappraisal blocks. However, reappraisal is one of the key strategies taught during $\mathrm{CBT}^{80}$ to which patients with panic disorder have been shown to be particularly responsive, even after only one treatment session. ${ }^{81}$ It is possible that having trained patients to successfully use reappraisal before scanning has provided them with sufficient, healthy regulation strategies. Furthermore, our results allow no final conclusions with respect to the exact role of the panic-specific processing patterns observed here in the onset and maintenance of an anxiety disorder. Future studies will have to establish whether these patterns of activity are sensitive to treatment, and whether any changes in these parameters are causally related to clinical improvement, which would confirm their proposed role as key mechanisms in the pathogenesis of anxiety.

\section{CONFLICT OF INTEREST}

$\mathrm{CJH}$ has valueless shares in p1vital and serves on their advisory panel. She has received consultancy payments from p1vital, Servier, Eli-Lilly, Astra Zeneca, Lundbeck and is a director of Oxford Psychologists Ltd. The remaining authors declare no conflict of interest.

\section{ACKNOWLEDGMENTS}

This study was supported by a grant from the Medical Research Council, UK awarded to $\mathrm{CJH}$ (G0501223) and a fellowship from the German Research Foundation granted to $A R$. CB was supported by a Lord-Florey Scholarship of the Berrow Foundation, BH and PT were in receipt of financial support from the MRC. NF is currently funded by the HDH Wills 1965 Charitable Trust, and AR is funded by MQ: Transforming Mental Health.

\section{REFERENCES}

1 Kessler RC, Berglund P, Demler O, Jin R, Merikangas KR, Walters EE. Lifetime prevalence and age-of-onset distributions of DSM-IV disorders in the National Comorbidity Survey Replication. Arch Gen Psychiatry 2005; 62: 593-602.

2 Greenberg PE, Sisitsky T, Kessler RC, Finkelstein SN, Berndt ER, Davidson JR et al. The economic burden of anxiety disorders in the 1990s. J Clin Psychiatry 1999; 60: 427-435.

3 Koopmans GT, Donker MC, Rutten FH. Common mental disorders and use of general health services: a review of the literature on population-based studies. Acta Psychiatr Scand 2005; 111: 341-350.

4 Wittchen HU, Jacobi F, Rehm J, Gustavsson A, Svensson M, Jonsson B et al. The size and burden of mental disorders and other disorders of the brain in Europe 2010. Eur Neuropsychopharmacol 2011; 21: 655-679.

5 Bruce SE, Yonkers KA, Otto MW, Eisen JL, Weisberg RB, Pagano M et al. Influence of psychiatric comorbidity on recovery and recurrence in generalized anxiety disorder, social phobia, and panic disorder: a 12-year prospective study. Am J Psychiatry 2005; 162: 1179-1187.

6 Hans E, Hiller W. A meta-analysis of nonrandomized effectiveness studies on outpatient cognitive behavioral therapy for adult anxiety disorders. Clin Psychol Rev 2013; 33: 954-964.

7 Barlow DH, Allen LB, Choate ML. Toward a unified treatment for emotional disorders. Behav Ther 2004; 35: 205-230.

8 Craske MG, Liao B, Brown L, Vervliet B. Role of inhibition in exposure therapy. J Exp Psychopathol 2012; 3: 322-345.

9 Beauregard M. Mind does really matter: evidence from neuroimaging studies of emotional self-regulation, psychotherapy, and placebo effect. Prog Neurobiol 2007; 81: 218-236.

10 Ochsner KN, Silvers JA, Buhle JT. Functional imaging studies of emotion regulation: a synthetic review and evolving model of the cognitive control of emotion. Ann N Y Acad Sci 2012; 1251: E1-24.

11 Ochsner KN, Bunge SA, Gross JJ, Gabrieli JD. Rethinking feelings: an FMRI study of the cognitive regulation of emotion. J Cogn Neurosci 2002; 14: 1215-1229.

12 Phan KL, Fitzgerald DA, Nathan PJ, Moore GJ, Uhde TW, Tancer ME. Neural substrates for voluntary suppression of negative affect: a functional magnetic resonance imaging study. Biol Psychiatry 2005; 57: 210-219.

13 Bishop SJ. Neurocognitive mechanisms of anxiety: an integrative account. Trends Cogn Sci 2007; 11: 307-316.

14 Kent JM, Rauch SL. Neurocircuitry of anxiety disorders. Curr Psychiatry Rep 2003; 5: 266-273.

15 Bishop SJ. Trait anxiety and impoverished prefrontal control of attention. Nat Neurosci 2009; 12: 92-98.

16 Ray RD, Ochsner KN, Cooper JC, Robertson ER, Gabrieli JD, Gross JJ. Individual differences in trait rumination and the neural systems supporting cognitive reappraisal. Cogn Affect Behav Neurosci 2005; 5: 156-168. 
17 Goossens L, Sunaert S, Peeters R, Griez EJ, Schruers KR. Amygdala hyperfunction in phobic fear normalizes after exposure. Biol Psychiatry 2007; 62: 1119-1125.

18 Phan KL, Fitzgerald DA, Nathan PJ, Tancer ME. Association between amygdala hyperactivity to harsh faces and severity of social anxiety in generalized social phobia. Biol Psychiatry 2006; 59: 424-429.

19 Straube T, Mentzel HJ, Miltner WHR. Neural mechanisms of automatic and direct processing of phobogenic stimuli in specific phobia. Biol Psychiatry 2006; 59: 162-170.

20 Bystritsky A, Pontillo D, Powers M, Sabb FW, Craske MG, Bookheimer SY. Functional MRI changes during panic anticipation and imagery exposure. Neuroreport 2001; 12: 3953-3957.

21 van den Heuvel OA, Veltman DJ, Groenewegen HJ, Witter MP, Merkelbach J, Cath DC et al. Disorder-specific neuroanatomical correlates of attentional bias in obsessive-compulsive disorder, panic disorder, and hypochondriasis. Arch Gen Psychiatry 2005; 62: 922-933.

22 Paulesu E, Sambugaro E, Torti T, Danelli L, Ferri F, Scialfa G et al. Neural correlates of worry in generalized anxiety disorder and in normal controls: a functional MRI study. Psychol Med 2010; 40: 117-124.

23 Nakao T, Nakagawa A, Yoshiura T, Nakatani E, Nabeyama M, Yoshizato C et al. Brain activation of patients with obsessive-compulsive disorder during neuropsychological and symptom provocation tasks before and after symptom improvement: a functional magnetic resonance imaging study. Biol Psychiatry 2005; 57: 901-910.

24 Paquette V, Levesque J, Mensour B, Leroux JM, Beaudoin G, Bourgouin P et al. "Change the mind and you change the brain": effects of cognitive-behavioral therapy on the neural correlates of spider phobia. Neuroimage 2003; 18: 401-409.

25 Stein MB, Goldin PR, Sareen J, Zorrilla LT, Brown GG. Increased amygdala activation to angry and contemptuous faces in generalized social phobia. Arch Gen Psychiatry 2002; 59: 1027-1034.

26 Blair KS, Geraci M, Korelitz K, Otero M, Towbin K, Ernst M et al. The pathology of social phobia is independent of developmental changes in face processing. $\mathrm{Am} J$ Psychiatry 2011; 168: 1202-1209.

27 Goldin PR, Manber T, Hakimi S, Canli T, Gross JJ. Neural bases of social anxiety disorder emotional reactivity and cognitive regulation during social and physical threat. Arch Gen Psychiatry 2009; 66: 170-180.

28 Hofmann SG, Ellard KK, Siegle GJ. Neurobiological correlates of cognitions in fear and anxiety: a cognitive-neurobiological information-processing model. Cogn Emot 2012; 26: 282-299.

29 Shin LM, Liberzon I. The neurocircuitry of fear, stress, and anxiety disorders. Neuropsychopharmacology 2010; 35: 169-191.

30 Clark DM, Wells A. A cognitive model of social phobia. In: Heimberg RG, Liebowitz MR, Hope D (eds). Social Phobia-Diagnosis, Assessment, and Treatment. Guilford: New York, NY, USA, 1995, pp 69-93.

31 Salkovskis PM, Clark DM, Hackmann A, Wells A, Gelder MG. An experimental investigation of the role of safety-seeking behaviours in the maintenance of panic disorder with agoraphobia. Behav Res Ther 1999; 37: 559-574.

32 Levitt JT, Brown TA, Orsillo SM, Barlow DH. The effects of acceptance versus suppression of emotion on subjective and psychophysiological response to carbon dioxide challenge in patients with panic disorder. Behav Ther 2004; 35: 747-766.

33 Hayes SC, Strosahl KD, Wilson KG. Acceptance and Commitment Therapy: An Experiental Approach to Behavior Change. Guilford Press: New York, NY, USA, 1999.

34 Klumpp H, Fitzgerald DA, Phan KL. Neural predictors and mechanisms of cognitive behavioral therapy on threat processing in social anxiety disorder. Prog Neuropsychopharmacol Biol Psychiatry 2013; 45: 83-91.

35 Mansson KN, Carlbring P, Frick A, Engman J, Olsson CJ, Bodlund $\mathrm{O}$ et al. Altered neural correlates of affective processing after internet-delivered cognitive behavior therapy for social anxiety disorder. Psychiatry Res 2013; 214: 229-237.

36 Ball TM, Ramsawh HJ, Campbell-Sills L, Paulus MP, Stein MB. Prefrontal dysfunction during emotion regulation in generalized anxiety and panic disorders. Psychol Med 2013; 43: 1475-1486.

37 Friedman $\mathrm{BH}$, Thayer JF. Autonomic balance revisited: panic anxiety and heart rate variability. J Psychosom Res 1998; 44: 133-151.

38 Shapiro PA, Sloan RP, Bigger JT, Bagiella E, Gorman JM. Cardiac denervation and cardiovascular reactivity to psychological stress. Am J Psychiatry 1994; 151: $1140-1147$

39 Thayer JF, Brosschot JF. Psychosomatics and psychopathology: looking up and down from the brain. Psychoneuroendocrinology 2005; 30: 1050-1058.

40 Alvares GA, Quintana DS, Kemp AH, Van Zwieten A, Balleine BW, Hickie IB et al. Reduced heart rate variability in social anxiety disorder: associations with gender and symptom severity. PLoS One 2013; 8: e70468.

41 Garakani A, Martinez JM, Aaronson CJ, Voustianiouk A, Kaufmann H, Gorman JM. Effect of medication and psychotherapy on heart rate variability in panic disorder. Depress Anxiety 2009; 26: 251-258.
42 American Psychiatric Association. Diagnostic and Statistical Manual of Mental Disorders, Fourth Edition: DSM-IV-TR. American Psychiatric Associaiton: Washington, DC, 2000

43 Reinecke A, Cooper M, Favaron E, Massey-Chase R, Harmer C. Attentional bias in untreated panic disorder. Psychiatry Res 2011; 185: 387-393.

44 First MB, Spitzer RL, Gibbon M, Williams JBW. Structured Clinical Interview for DSM-IV Axis I Disorders, Clinician Version (SCID-CV). American Psychiatry Press: Washington, DC, USA, 1996.

45 Nelson HE. National Adult Reading Test (NART): Test Manual. NFER-Nelson: Windsor, UK, 1982

46 Zigmond AS, Snaith RP. The Hospital Anxiety and Depression Scale. Acta Psychiatr Scand 1983; 67: 361-370.

47 Chambless DL, Caputo GC, Bright P, Gallagher R. Assessment of fear of fear in agoraphobics - the Body Sensations Questionnaire and the Agoraphobic Cognitions Questionnaire. J Consult Clin Psychol 1984; 52: 1090-1097.

48 Lang PJ, Bradley MM, Cuthbert BN. International Affective Picture System (IAPS): Technical Manual and Affective Ratings. National Institute of Mental Health Centre for the Study of Emotion and Attention: Gainesville, FL, USA, 1997.

49 Western DG. Bioelectric signal analysis to expose nervous control of the human heart. PhD Thesis, University College London, London, UK, 2012.

50 Di Simplicio M, Costoloni G, Western D, Hanson B, Taggart P, Harmer CJ. Decreased heart rate variability during emotion regulation in subjects at risk for psychopathology. Psychol Med 2012; 42: 1775-1783.

51 Jenkinson M, Bannister P, Brady M, Smith S. Improved optimization for the robust and accurate linear registration and motion correction of brain images. Neuroimage 2002; 17: 825-841.

52 Smith SM. Fast robust automated brain extraction. Hum Brain Mapp 2002; 17: 143-155.

53 Woolrich MW, Ripley BD, Brady M, Smith SM. Temporal autocorrelation in univariate linear modeling of FMRI data. Neuroimage 2001; 14: 1370-1386.

54 Beckmann CF, Jenkinson M, Smith SM. General multilevel linear modeling for group analysis in FMRI. Neuroimage 2003; 20: 1052-1063.

55 Reinecke A, Harmer C. A cognitive-neuropsychological account of treatment action in anxiety: can we augment clinical efficacy? Psychopathol Rev. (in press).

56 Robinson OJ, Charney DR, Overstreet C, Vytal K, Grillon C. The adaptive threat bias in anxiety: amygdala-dorsomedial prefrontal cortex coupling and aversive amplification. Neuroimage 2012; 60: 523-529.

57 Cremers HR, Demenescu LR, Aleman A, Renken R, van Tol M-J, van der Wee NJA et al. Neuroticism modulates amygdala-prefrontal connectivity in response to negative emotional facial expressions. Neuroimage 2010; 49: 963-970.

58 Demenescu LR, Kortekaas R, Cremers HR, Renken RJ, van Tol MJ, van der Wee MJA et al. Amygdala activation and its functional connectivity during perception of emotional faces in social phobia and panic disorder. J Psychiatric Res 2013; 47: 1024-1031.

59 Etkin A. Functional Neuroanatomy of Anxiety: A Neural Circuit Perspective. In: Stein MB, Steckler T (eds). Behavioral Neurobiology of Anxiety and Its Treatment. Vol 2, Springer-Verlag Berlin: Heidelberg, Germany, 2009, pp 251-277.

60 Etkin A, Wager TD. Functional neuroimaging of anxiety: a meta-analysis of emotional processing in PTSD, social anxiety disorder, and specific phobia. Am J Psychiatry 2007; 164: 1476-1488.

61 Larson CL, Schaefer HS, Siegle GJ, Jackson CA, Anderle MJ, Davidson RJ. Fear is fast in phobic individuals: amygdala activation in response to fear-relevant stimuli. Biol Psychiatry 2006; 60: 410-417.

62 Straube T, Mentzel HJ, Miltner WH. Common and distinct brain activation to threat and safety signals in social phobia. Neuropsychobiology 2005; 52: 163-168.

63 Botvinick M, Nystrom LE, Fissell K, Carter CS, Cohen JD. Conflict monitoring versus selection-for-action in anterior cingulate cortex. Nature 1999; 402: 179-181.

64 Holroyd CB, Coles MGH. The neural basis. of human error processing: reinforcement learning, dopamine, and the error-related negativity. Psychol Rev 2002; 109: 679-709.

65 Kalisch R, Gerlicher AMV. Making a mountain out of a molehill: on the role of the rostral dorsal anterior cingulate and dorsomedial prefrontal cortex in conscious threat appraisal, catastrophizing, and worrying. Neurosci Biobehav Rev 2014; 42: $1-8$.

66 Posner MI, Petersen SE. The attention system of the human brain. Annu Rev Neurosci 1990; 13: 25-42.

67 Robinson OJ, Krimsky M, Lieberman L, Allen P, Vytal K, Grillon C. The dorsal medial prefrontal (anterior cingulate) cortex-amygdala aversive amplification circuit in unmedicated generalised and social anxiety disorders: an observational study. Lancet Psychiatry 2014; 1: 294-302.

68 Taylor SF, Phan KL, Decker LR, Liberzon I. Subjective rating of emotionally salient stimuli modulates neural activity. Neuroimage 2003; 18: 650-659.

69 Carlson JM, Cha J, Mujica-Parodi LR. Functional and structural amygdala-anterior cingulate connectivity correlates with attentional bias to masked fearful faces. Cortex 2013; 49: 2595-2600. 
70 Schienle A, Schafer A, Hermann A, Rohrmann S, Vaitl D. Symptom provocation and reduction in patients suffering from spider phobia: an fMRI study on exposure therapy. Eur Arch Psychiatry Clin Neurosci 2007; 257: 486-493.

71 Berkman ET, Lieberman MD. Using neuroscience to broaden emotion regulation: theoretical and methodological considerations. Soc Personal Psychol Compass 2009; 3: 475-493.

72 Goldin PR, McRae K, Ramel W, Gross JJ. The neural bases of emotion regulation: reappraisal and suppression of negative emotion. Biol Psychiatry 2008; 63: 577-586.

73 Aron AR, Robbins TW, Poldrack RA. Inhibition and the right inferior frontal cortex. Trends Cogn Sci 2004; 8: 170-177.

74 Phillips ML, Ladouceur CD, Drevets WC. A neural model of voluntary and automatic emotion regulation: implications for understanding the pathophysiology and neurodevelopment of bipolar disorder. Mol Psychiatry 2008; 13: 833-857.

75 Etkin A, Egner T, Peraza DM, Kandel ER, Hirsch J. Resolving emotional conflict: a role for the rostral anterior cingulate cortex in modulating activity in the amygdala. Neuron 2006; 51: 871-882.

76 Milad MR, Wright Cl, Orr SP, Pitman RK, Quirk GJ, Rauch SL. Recall of fear extinction in humans activates the ventromedial prefrontal cortex and hippocampus in concert. Biol Psychiatry 2007; 62: 446-454.

77 Phelps EA, Delgado MR, Nearing KI, LeDoux JE. Extinction learning in humans: role of the amygdala and vmPFC. Neuron 2004; 43: 897-905.
78 Resick PA, Miller MW. Posttraumatic stress disorder: anxiety or traumatic stress disorder? J Trauma Stress 2009; 22: 384-390.

79 Stein DJ, Craske MG, Friedman MJ, Phillips KA. Meta-structure issues for the DSM-5: how do anxiety disorders, obsessive-compulsive and related disorders, post-traumatic disorders, and dissociative disorders fit together? Curr Psychiatry Rep 2011; 13: 248-250.

80 Frewen PA, Dozois DJ, Lanius RA. Neuroimaging studies of psychological interventions for mood and anxiety disorders: empirical and methodological review. Clin Psychol Rev 2008; 28: 228-246.

81 Reinecke A, Waldenmaier L, Cooper MJ, Harmer CJ. Changes in automatic threat processing precede and predict clinical changes with exposurebased cognitive-behavior therapy for panic disorder. Biol Psychiatry 2013; 73: 1064-1070.

This work is licensed under a Creative Commons Attribution 4.0 International License. The images or other third party material in this article are included in the article's Creative Commons license, unless indicated otherwise in the credit line; if the material is not included under the Creative Commons license, users will need to obtain permission from the license holder to reproduce the material. To view a copy of this license, visit http://creativecommons.org/licenses/ by/4.0/ 